\title{
Laparoscopic Living-Donor Nephrectomy of a Horseshoe Kidney: A Case Report and Review of the Literature
}

\author{
Daniel Galvez, Justin Steggerda, Derrick Christopher, Daniel Borja-Cacho and Joseph Leventhal *
}

check for updates

Citation: Galvez, D.; Steggerda, J.; Christopher, D.; Borja-Cacho, D.; Leventhal, J. Laparoscopic Living-Donor Nephrectomy of a Horseshoe Kidney: A Case Report and Review of the Literature. Transplantology 2021, 2, 455-459. https://doi.org/10.3390/ transplantology2040043

Academic Editor:

Wisit Cheungpasitporn

Received: 27 August 2021

Accepted: 3 November 2021

Published: 5 November 2021

Publisher's Note: MDPI stays neutral with regard to jurisdictional claims in published maps and institutional affiliations.

Copyright: (C) 2021 by the authors. Licensee MDPI, Basel, Switzerland. This article is an open access article distributed under the terms and conditions of the Creative Commons Attribution (CC BY) license (https:/ / creativecommons.org/licenses/by/ $4.0 /)$.
Department of Surgery, Division of Transplantation, Northwestern Memorial Hospital, Chicago, IL 60611, USA; daniel.galvezlima@nm.org (D.G.); justin.steggerda@nm.org (J.S.); derrick.christopher@nm.org (D.C.); daniel.borja-cacho@nm.org (D.B.-C.)

* Correspondence: jleventh@nm.org

\begin{abstract}
We present the case of a living-donor nephrectomy of a horseshoe kidney. The recipient was a 33-year-old male with a history of end-stage renal disease secondary to IgA nephropathy. The donor was his 33-year-old partner who on preoperative cross-sectional imaging was found to have a horseshoe kidney with a single artery, vein and ureter. The donor operation was performed using a laparoscopic hand-assisted technique with transection of the interpolar fibrotic band using a stapler device. The backtable organ preparation was performed in a standard fashion with addition of a reinforcing hemostatic suture of the stapled fibrotic band. The donated kidney was transplanted extraperitoneally in the right iliac fossa of the recipient. The patient had an unremarkable postoperative course and was discharged home on post operative day 2 with normalizing renal function. To our knowledge, this is the first living donor nephrectomy of a horseshoe kidney performed using a laparoscopic hand-assisted technique.
\end{abstract}

Keywords: horseshoe kidney; donor nephrectomy; kidney transplant

\section{Introduction}

A horseshoe kidney (HSK) is the most frequent renal fusion anomaly ( 1 in 400 to 800) [1-10] that involves abnormal migration of both kidneys with concomitant polar fusion. In over $90 \%$ of the cases this fusion occurs at the lower poles and as a result, two separate excretory renal units are maintained. The isthmus-which represents the fused portion-can be composed of renal parenchyma or a fibrous band and it may lie over or lateral to the midline. Because of this early fusion the kidneys fail to rotate medially during embryogenesis resulting in a ventral position of the renal pelvis with the ureters coursing in front of the lower poles. This may lead to abnormalities in the collecting system, therefore: urinary tract infections, vesicoureteral reflux, recurrent kidney stones and hydronephrosis, may frequently be observed [2,5-7]. Variation in the origin, number and size of the renal arteries and veins is well known and described as well, with only $30 \%$ of all HSK having a single renal artery on each side [5,7-9].

Due to all of this, concern for safety and feasibility of a living donor HSK has been questioned. However, according to the literature, since 1998, ten cases of successful HSK transplantation from live donors have been published ( 9 out of 10 from countries where deceased donation is not available) $[1,11]$. Outcomes are comparable with standard nonHSK donation with the most common complication reported being urinary leaks, likely due to the anterior situation of the urinary pelvis and the transected renal parenchyma $[2,4,5,11]$.

Thorough pre-operative planning is paramount for a safe and successful operation. The protocol at our institution mandates a renal scintigraphy using technetium-99m-DTPA to estimate a relative glomerular filtration rate (GFR) for each kidney, in addition to a dynamic CT angiogram to assess renal morphology, vasculature and the excretory system. 


\section{Case Report}

We present the case of a 33-year-old male with a history of end-stage renal disease secondary to IgA nephropathy who had been on hemodialysis for 3 months. Transplant evaluation deemed him an adequate candidate for transplantation, with his 33-year-old partener interested in living donation. She had no previous medical history and was found to have normal renal function. Technetium-99m-DTPA renal scintigraphy revealed estimated relative GFR values of $54.5 \%$ on the left and $45.5 \%$ on the right, in addition to a HSK (Figure 1). A dynamic CT angiogram showed contiguous renal parenchyma crossing the midline between the aorta and the inferior mesenteric artery, single right and left ureters, single right and left renal arteries, two right renal veins and a single left renal vein (Figure 2), in addition to volumetric reconstruction imaging (Figure 3). The left kidney was chosen for donation.
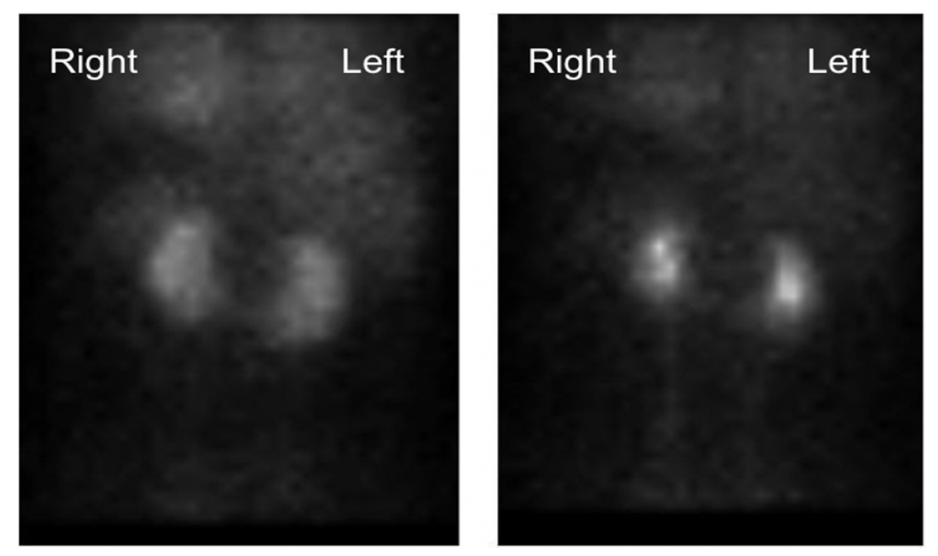

Figure 1. Technetium-99m-DTPA renal scintigraphy revealing an estimated relative GFR values of $54.5 \%$ on the left and $45.5 \%$ on the right, in addition to a HSK.

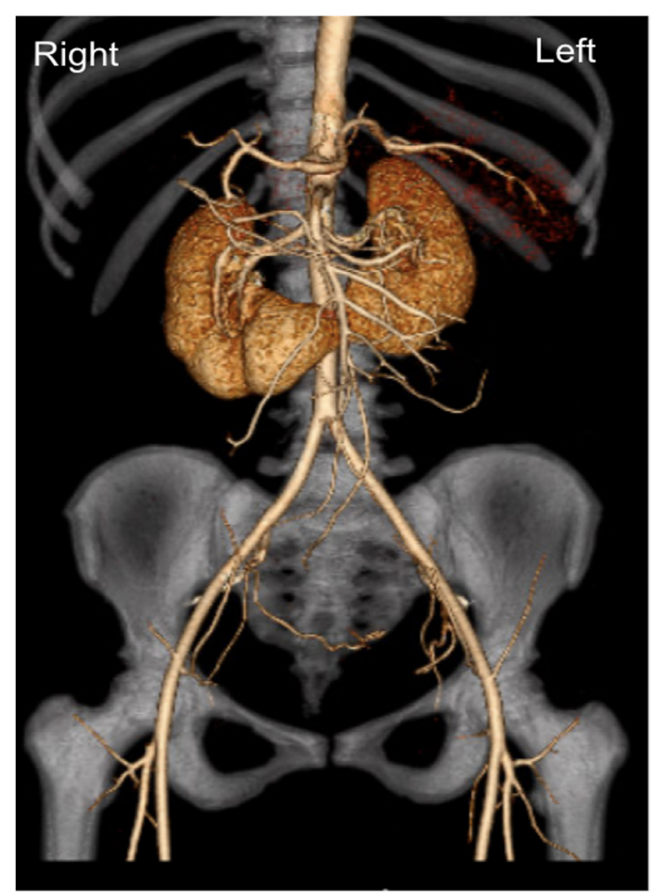

Figure 2. Dynamic CT angiogram with 3D reconstruction showing contiguous renal parenchyma crossing the midline between the aorta and the inferior mesenteric artery; single right and left renal arteries. 


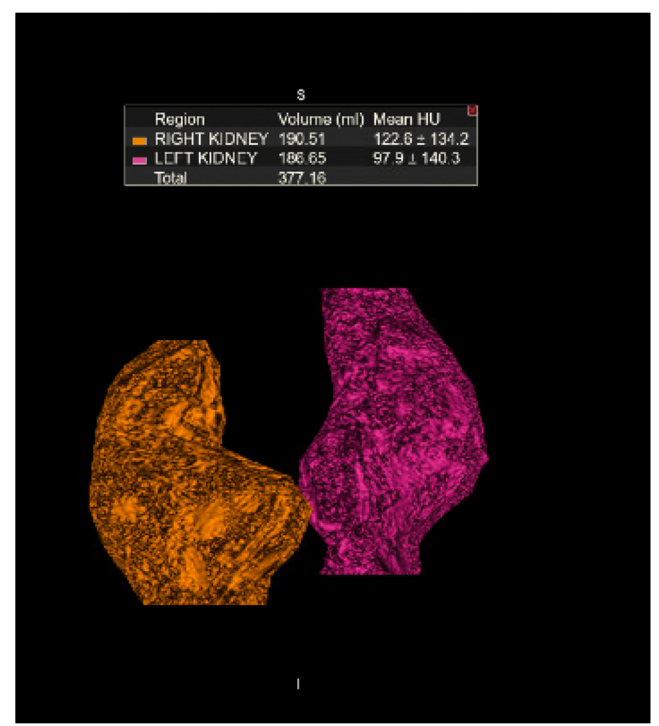

Figure 3. Volumetric CT reconstruction of the kidneys measuring $190.51 \mathrm{~mL}$ for the right kidney and $186.65 \mathrm{~mL}$ for the left kidney.

The donor operation was performed using a laparoscopic hand-assisted nephrectomy technique. After hilar dissection and isolation of the renal vasculature, the inter-polar fibrotic band was identified and transected at the midline using a vascular stapling device (Medtronic GIA $^{\text {TM }}$ Stapler Minneapolis, MN, USA). Hemostasis was confirmed without the need of further parenchymal hemostatic techniques and the donor nephrectomy was completed. On the backtable, the organ was prepared for transplantation in a standard fashion, with the addition of a reinforcing hemostatic running suture of the stapled fibrotic band using 6-0 permanent suture (Figure 4).

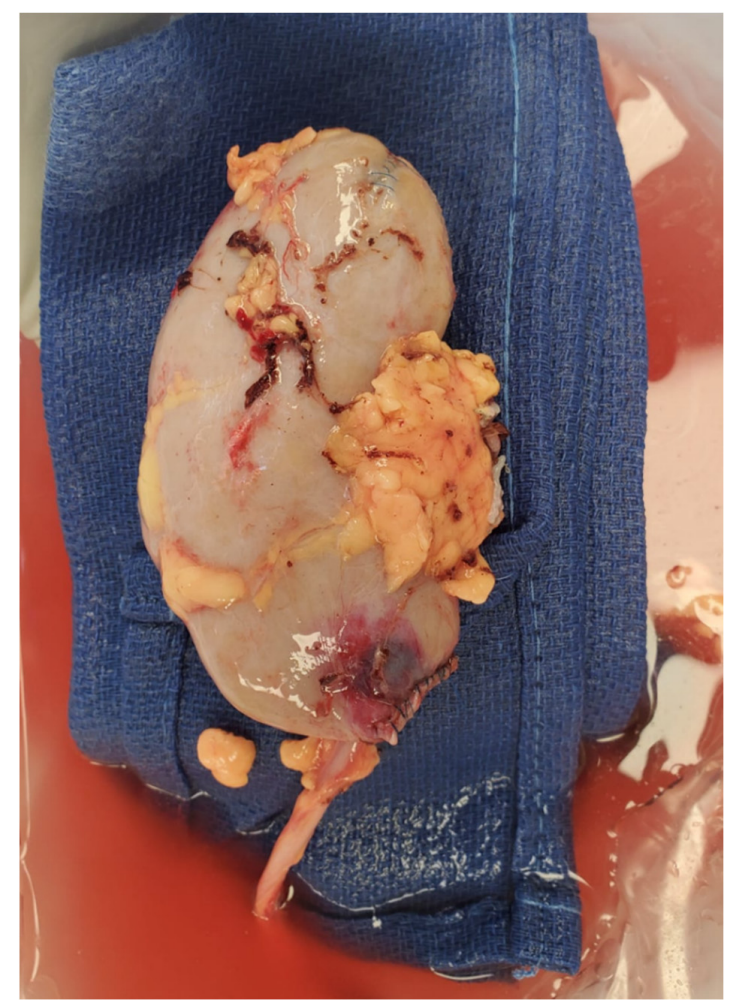

Figure 4. Picture of the explanted left kidney after backbench organ preparation. Note that the lower pole fibrotic band has been reinforced with a hemostatic running suture. 
The donated kidney was transplanted extraperitoneally in the right iliac fossa, with the renal vein and renal artery anastomosed to the external iliac vein and artery respectively. A ureteroneocystostomy over a 6 Fr. double-J-stent was performed using the Lich-Gregoir technique. Induction immunosuppression therapy consisted of $20 \mathrm{mg}$ of alemtuzumab administered upon incision. Tacrolimus, mycophenolate mofetil and methylprednisolone with a prednisone taper were used for maintenance immunosuppression. The patient had an unremarkable postoperative course and was discharged home on post operative day 2 with a creatinine level of $2.0 \mathrm{mg} / \mathrm{dL}$, down from a preoperative level of $5.6 \mathrm{mg} / \mathrm{dL}$. He was re-admitted to the hospital on post operative day 12 with mild acute kidney injury (AKI) and mild hydronephrosis secondary to ureteral stent obstruction. The stent was removed with rapid resolution of the AKI.

\section{Discussion}

Given the high likelihood of complex anatomical variation of HSK, both vascular and of the excretory system, the experience with these kidneys for living donation remains limited. The first split transplant of a HSK was performed by Politano in $1963[3,8,10]$ and since then successful transplantation of both en-bloc and split horseshoe kidneys from deceased donors has been described with comparable outcomes to non-HSK $[3,8,10,11]$. In contrast to this experience, according to the literature, only 10 cases of successful living donation of HSK have been described [11]. Table 1. To our knowledge, this is the first case described using the laparoscopic hand-assisted technique.

Table 1. Living donor horseshoe kidney transplants described in the literature.

\begin{tabular}{cccc}
\hline Author & Year & Surgical Approach & Complications \\
\hline Aikawa & 1998 & Open (midline transperitoneal) & Urine leak \\
Inoue & 2000 & Open (left flank transperitoneal) & Urine leak \\
Noyal & 2003 & Open (left flank transperitoneal). & Urine leak \\
Huser & 2005 & None & None \\
Dinckan & 2007 & Open (left flank transperitoneal) & Ureteral obstruction \\
Sezer & 2013 & Open (retroperitoneal lumbotomy) & None reported \\
Kumar & 2015 & Open (left flank transperitoneal) & None \\
Justo-Janeiro & 2015 & Open (midline transperitoneal) & None \\
Sozener & 2018 & Open (left flank transperitoneal) & None \\
Galvez & 2021 & Laparoscopic hand-assisted & . \\
\hline
\end{tabular}

At our institution, all patients evaluated for potential renal living donation undergo a technetium-99m-DTPA renal scintigraphy to determine estimated GFR of each kidney, as well as dynamic CT angiogram to delineate vascular and excretory system anatomy. We consider this paramount to identify suitable donors, as well as for preoperative surgical planning.

The laparoscopic hand-assisted technique is safe and adds the benefits of a minimally invasive approach. The interpolar renal tissue can be safely divided with a laparoscopic stapling device and can later be reinforced with a running hemostatic suture in the backtable. Given the higher rate of urine leaks, particular attention should be paid to the transected interpolar tissue, both on the donor as well as the recipient, with addition of a running hemostatic suture of this tissue, as well as the use of an external drainage device.

\section{Conclusions}

Living donor nephrectomy of a HSK using a minimally invasive approach is a feasible operation with comparable outcomes to standard donation. Preoperative high-quality imaging that identifies location and morphology of the isthmus, as well as any vascular and excretory system variation, is paramount for successful outcomes. 
Author Contributions: D.G.: Project administration, Conceptualization, Investigation, Writingoriginal draft, Writing—review \& editing. J.S.: Writing—review \& editing. D.C.: review \& editing. D.B.-C.: review \& editing. J.L.: Conceptualization, Methodology, Writing-review \& editing. All authors have read and agreed to the published version of the manuscript.

Funding: This research received no external funding.

Institutional Review Board Statement: Ethical review and approval were waived for this study. Northwestern policy indicates that Case Report Studies are not considered to be human research in nature, as there were no interventions made with research intent. Hence, IRB approval is not required.

Informed Consent Statement: Not applicable.

Data Availability Statement: Not applicable.

Conflicts of Interest: The authors declare no conflict of interest.

\section{References}

1. Kaabak, M.M.; Babenko, N.N.; Zokoev, A.K.; Khovrin, V.V.; Galyan, T.N. Renal Transplantation From a Living Donor with a Horseshoe Kidney. Transplant. Direct 2016, 2, e53. [CrossRef] [PubMed]

2. Dinckan, A.; Tekin, A.; Turkyilmaz, S.; Kocak, H.; Gurkan, A.; Erdogan, O.; Tuncer, M.; Demirbas, A.; Malek-Hosseini, S.A. Horseshoe kidney for transplant: Report of 3 cases. Exp. Clin. Transplant. Off. J. Middle East Soc. Organ Transplant. 2007, 5, 716-719.

3. Sezer, T.O.; Solak, I.; Sozbilen, M.; Firat, O.; Yilmaz, M.; Toz, H.; Sarsik, B.; Isayev, C.; Harman, M.; Hoscoskun, C. A horseshoe kidney from a live donor as a renal transplant: Case report. Exp. Clin. Transplant. 2013, 11, 454-457. [CrossRef] [PubMed]

4. Justo-Janeiro, J.M.; Orozco, E.P.; Reyes, F.J.; de la Rosa Paredes, R.; de Lara Cisneros, L.G.; Espinosa, A.L.; Naylor, J.M. Transplantation of a horseshoe kidney from a living donor: Case report, long term outcome and donor safety. Int. J. Surg. Case Rep. 2015, 15, 21-25. [CrossRef]

5. Kikkawa, K.; Wakamiya, T.; Kusumoto, H.; Matsumura, N.; Kohjimoto, Y.; Hara, I. Transplantation of Horseshoe Kidney from Living, Genetically Unrelated Donor. Case Rep. Transplant. 2015, 2015, 390381. [CrossRef]

6. Inoue, S.; Imai, K.; Kuzuhara, K.; Ootubo, O.; Yamada, A. Use of horseshoe kidney as renal transplant from living donor: Its surgical feasibility and pitfalls. Transplant. Proc. 2000, 32, 1586-1588. [CrossRef]

7. Ordones, F.V.; Yamamoto, H.; Pajolli, P.I.; Meduna, R.R.; Gomes Filho, F.F.; Guerra, R.; Amaro, J.L.; Kawano, P.R. Transplanting a horseshoe kidney: A case report and review of surgical strategies. Urol. Case Rep. 2018, 21, 119. [CrossRef] [PubMed]

8. Pontinen, T.; Khanmoradi, K.; Kumar, A.; Kudsi, H.; Chewaproug, D.; Zaki, R.; Ortiz, J. Horseshoe kidneys: An underutilized resource in kidney transplant. Exp. Clin. Transplant. Off. J. Middle East Soc. Organ Transplant. 2010, 8, 74-78.

9. Iwanaga, J.; Saga, T.; Tabira, Y.; Watanabe, K.; Yamaki, K.I. Contrast imaging study of the horseshoe kidney for transplantation. Surg. Radiol. Anat. 2015, 37, 1267-1271. [CrossRef] [PubMed]

10. Nemes, B.; Kanyári, Z.; Zádori, G.; Zsom, L.; Berhés, M.; Hamar, M.; Kóbor, K.; Péter, A. Horseshoe kidney transplantation. Interv. Med. Appl. Sci. 2015, 7, 85-89. [CrossRef] [PubMed]

11. Sozener, U. Transplantation of a horseshoe kidney from a living donor using stapler for transsection. J. Surg. Case Rep. 2019, 2019, rjz299. [CrossRef] [PubMed] 